\title{
Pen injected apomorphine against off phenomena in late Parkinson's disease: a double blind, placebo controlled study
}

\author{
L Østergaard, L Werdelin, P Odin, O Lindvall, E Dupont, P B Christensen, E Boisen, \\ N B Jensen, S H Ingwersen, M Schmiegelow
}

Neurology, Viborg

Hospital, Viborg,

Denmark

N B Jensen

Department of

Neurology, University

Hospital, Lund,

Sweden

P Odin

O Lindvall

Department of

Pharmacokinetics

$S$ H Ingwersen

Department of Clinical

Development, Novo

Nordisk AVS,

Copenhagen, Denmark

$M$ Schmiegelow

Correspondence to:

Dr L Werdelin, Department

of Neurology, Frederiksberg

Hospital, Nordre Fasanvej

59, DK-2000 Frederiksberg, Denmark.

Received 21 February 1994

and in final revised form

31 January 1995

Accepted 8 February 1995

\begin{abstract}
Department of
Neurology, Hvidovre

Hospital, University of

Copenhagen,

Copenhagen, Denmark

L Østergaard

L Werdelin

Department of

Neurology, Aarhus

University Hospital,

Aarhus, Denmark

E Dupont

P B Christensen

Department of

Neurology,

Sønderborg Hospital,

Sønderborg, Denmark

E Boisen

Department of

Abstract

The effect, therapeutic dose range, and pharmacokinetics of apomorphine, given as subcutaneous injections by a single use pen, were evaluated in the treatment of off phenomena in 22 patients with idiopathic Parkinson's disease. At study entry a placebo controlled apomorphine test was performed, and apomorphine doses were then individually titrated (mean 3.4 (range 0.8-6.0) $\mathrm{mg}$ ) and compared with placebo in a double blind cross over phase. With apomorphine compared with placebo the mean daily duration of off periods was reduced by $51 \%$ as assessed by the patients and by $58 \%$ as assessed by the staff. The severity of off periods was also significantly reduced. The effect was unchanged after a maintenance phase of eight weeks. At study termination 13 of 14 patients were able to inject themselves and 11 of 14 patients found that their feeling of freedom had increased. The most common adverse events were nausea, subcutaneous nodules, and increased frequency of involuntary movements. Pharmacokinetics were linear and did not change with repeat dosing. The $t_{\max }$ ranged from five to 45 minutes (16 patients).

It is concluded that pen injected apomorphine is a valuable treatment for patients with advanced Parkinson's disease with on-off phenomena.
\end{abstract}

$(\Im$ Neurol Neurosurg Psychiatry 1995;58:681-687)

Keywords: Parkinson's disease; apomorphine

In several studies of idiopathic Parkinson's disease the dopamine agonist apomorphine, a well known emeticum, has shown good effect on parkinsonian symptoms ${ }^{1-3}$ and on the "onoff" phenomena, ${ }^{4-9}$ probably due to activation of both $D_{1}$ and $D_{2}$ dopamine receptors. ${ }^{1011}$ Most of the studies, however, are anecdotal.

Subcutaneous apomorphine is preferred to oral treatment, as the substance is nephrotoxic in oral therapeutic doses. ${ }^{4} \mathrm{~A}$ few double blind, placebo controlled studies with subcutaneous injections of apomorphine have previously been carried out. ${ }^{12-15}$ To our knowledge the present study is the first to combine a placebo controlled test for dopaminergic responsiveness with a double blind, placebo controlled, cross over study of the effects of optimal doses of apomorphine given as subcutaneous bolus injections to patients with idiopathic Parkinson's disease with on-off phenomena.

\section{Patients}

Twelve women and 10 men with a mean age of 59.3 (range 44-76) years comprised the study group. They had had idiopathic Parkinson's disease for an average of 9.8 (range 3.4-19.2) years, and when in on phase they were in Hoehn and Yahr stages $2 \cdot 0-4 \cdot 0$. The mean duration of levodopa treatment was eight (range 3-19) years. Mean body weight was 69.9 (range $47 \cdot 0-98 \cdot 0$ ) $\mathrm{kg}$.

All patients had daily, disabling off periods, defined as change in motor state within five minutes, and described by the patient and by relatives or a physician. Diphasic dyskinesia was an exclusion criterion.

The patients were on a stable regimen of levodopa (plus carbidopa or benserazide) of five to 14 doses per day. Other drugs used for idiopathic Parkinson's disease related symptoms included bromocriptine (12 patients), selegiline (nine), amitriptyline (eight), baclofene (two), imipramine (two), and amantadine, benzhexol, and clozapine (one patient each). Seven patients had previously been treated with apomorphine, but no patients received apomorphine beyond the test preparation during the study period.

At study entry none of the patients had orthostatic hypotension or any other relevant, unstable physical or psychiatric disease, as documented by their medical history and a clinical examination.

\section{Methods}

DESIGN

The study was carried out at four centres in Denmark and one centre in Sweden. The patients were admitted to hospital at study entry. After an initial placebo controlled test of dopamine responsiveness (apomorphine test) on day 2 and a screening phase (minimum three days), doses of apomorphine were individually titrated in an open dose finding phase (maximum one week). The patients then entered a double blind cross over phase with a scheduled four day period of apomorphine treatment and four days of placebo, in randomised order. Hereafter they were 
discharged from hospital, and during an eight week maintenance phase came for visits to the clinic every second week. The study was terminated the day after the last apomorphine injections had been given (postdose).

\section{TEST PREPARATION}

Apomorphine was given as a preserved 10 $\mathrm{mg} / \mathrm{ml}$ solution ( $\mathrm{pH} 3-4)$, and isotonic saline was used as placebo. Injections were given by prefilled single use pens with a push button release system (NovoLet). Subcutaneous injection in the anterolateral femoral region or abdominal wall was recommended.

\section{DOSAGE REGIMEN}

Oral antiparkinsonian drugs were adjusted to an optimum at least one month before study entry, and dose changes or administration of extraneous levodopa as required during the study period were discouraged.

To avoid side effects such as nausea and vomiting and orthostatic hypotension induced by apomorphine, the peripheral dopamine antagonist domperidone (Motilium) was given orally ( $20 \mathrm{mg}$ three times daily), starting the day before the apomorphine test. We aimed at a reduction or withdrawal of domperidone during the maintenance phase.

Before the apomorphine test all antiparkinsonian drugs were discontinued for 12 hours during the night. The test was performed by giving increasing doses of $1 \cdot 6,3 \cdot 2,4 \cdot 8$, and $6.4 \mathrm{mg}$ apomorphine with an interval of at least 120 minutes. If unacceptable adverse events occurred with less than $6.4 \mathrm{mg}$, the dose was not further increased. One placebo dose was added to the dose regimen as dose 2, 3 , or 4 in a randomised manner. Full blinding of patients and investigators was obtained by the use of prefilled pens.

After a screening phase of at least three days with no apomorphine but with usual medication the patients were given $1 \mathrm{mg}$ apomorphine at off periods. Doses were increased by $1 \mathrm{mg}$ with at least 90 minute intervals, until the optimal effect on off phenomena was reached or intolerance to apomorphine occurred. This dose was maintained for a minimum of two days before entry to the cross over phase. The maximum single dose allowed was $12 \mathrm{mg}$ apomorphine and the maximum daily dose allowed was $100 \mathrm{mg}$.

During the cross over phase apomorphine in individual optimal doses or placebo were given for four days each, every time the patient was "off", and during the eight week maintenance phase the patients continued to take optimal doses of apomorphine at off periods. The patients were encouraged to take or ask for apomorphine injections as soon as off symptoms occurred, and a second injection was allowed in case of an unsatisfactory effect after 30 minutes.

\section{EFFICACY ASSESSMENTS}

Dopaminergic response

The dopaminergic response was evaluated by an apomorphine test. ${ }^{16-18}$ The following four variables were evaluated by the investigator immediately before and 30-45 minutes after each injection: (a) rigidity (wrists, elbows, neck, knees), (b) tremor (head, arms, and legs), both on a scale from 0 to 4,4 indicating severe affection; (c) time to make 20 hand turnings (each hand separately, tapping on knees); and (d) time to walk $7 \mathrm{~m}$ and back. A positive test response was defined as a significant effect in at least two of the four tests (minimum $25 \%$ reduction of score in tests 1 and 2 ; minimum $33 \%$ reduction in tests 3 and 4$).{ }^{19}$

\section{Effect on off periods}

The number, duration, and severity (mild, moderate, severe, immobile) of the off periods were recorded by a member of staff eight hours a day for two days during the screening period, during the last two days of the dose finding phase, daily during the cross over phase, and at each visit in the maintenance phase. The patients were asked to record on a diary card the number and duration of off periods, during all times awake, for three days of the screening phase, daily during the cross over phase, and for the first three days of each two week period in the maintenance phase.

\section{Clinical global impression}

At each of the four visits in the maintenance phase the physician evaluated the patient's global improvement compared with his condition at admission to the trial. A scale from 1 (very much improved) to 7 (very much worse) was used. ${ }^{20}$

Effect on idiopathic Parkinson's disease symptoms The effect on idiopathic Parkinson's disease symptoms was evaluated with the unified Parkinson's disease rating scale (UPDRS, version $3 \cdot 0,1987$ ) section I-IV, with the modification that the evaluation of activities of daily living (part II) was done for off periods only and motor examination (part III) during an on period only. ${ }^{21}$ Rating was done on the last day of the screening phase and at the week 4 and week 8 visits in the maintenance phase.

\section{SAFETY ASSESSMENTS}

The effect of apomorphine on the daily number, duration, and severity of involuntary movements during on periods was evaluated by a member of the staff, following the same time schedule as for the off periods. All other spontaneously reported adverse events were recorded, and their duration, severity, and relation to the study drug (probable, possible, unlikely) were evaluated. At each visit in the maintenance phase the injection sites were inspected for signs of local irritation.

Blood pressure and pulse supine (after three minutes) and standing (after one minute) were registered before study entry, 10 times during the study, and at study termination. Registration was done before and 15 minutes after apomorphine treatment.

Electrocardiography was carried out before study entry and three times during 
the study (about 30 minutes after apomorphine).

Laboratory tests (haematology, biochemistry, and urinalysis) were done before study entry, once during the study period, and at the end of the study.

\section{EVALUATION OF THE PEN}

The suitability of the NovoLet ${ }^{\circledR}$ pen was evaluated through patient questionnaires at visits on week 2 and week 8 of the maintenance phase.

\section{PHARMACOKINETICS}

Plasma samples for assay of apomorphine were obtained at three occasions: after the first and the third dose of apomorphine in the dose finding phase and after one dose after two weeks in the maintenance phase. At each occasion plasma was collected before the dose and $5,10,15,30,45,60,75$, and 90 minutes after the dose. Plasma was assayed for apomorphine by solid phase extraction and high performance liquid chromatography (HPLC) with fluorescence detection. The limit of sensitivity was $2 \mathrm{nmol} / \mathrm{l}$, and the intra-assay precision ranged from $13 \cdot 7 \%$ to $2 \cdot 2 \%$ (SH Ingwersen, unpublished results). The variables $C_{\max }, t_{\max }, t_{1 / 2}$, and area under the concentration-time curve (AUC) (from time 0 to infinite time) were estimated by non-compartmental methods with the TopFit V. 2.0 analysis program. ${ }^{22}$ When necessary, AUCs were corrected for apomorphine concentrations present from previous doses.

\section{STATISTICAL METHODS}

Statistical evaluations were performed on the efficacy variables of the cross over phase.

Data on off periods and involuntary movements were available from both subphases (apomorphine and placebo) for 17 patients from investigator assessments, and for 16 patients from diary card information.

Several patients could not complete all four days on placebo during the cross over phase. Therefore, to obtain comparable values, the total duration of off periods and periods of involuntary movements as well as the total number of off periods and periods of involuntary movements were divided by the number of days the patient was on either treatment. These end points were analysed by analysis of variance (ANOVA), including treatment, patient, period, and sequence of treatments as factors. Carry over effects were not considered, because apomorphine is rapidly eliminated. The daily number of off periods and periods of involuntary movements were logarithmically transformed before analysis to better conform with the normality assumption.

The severity of off periods and of involuntary movements were analysed by the MantelHaenszel test ${ }^{23}$ with patients as strata (a within patient comparison). For these tests no period effect was assumed.

Results are given as means (SD), unless otherwise indicated. A significance level of 0.05 was used throughout.

\section{ETHICAL CONSIDERATIONS}

The study was conducted in accordance with the Helsinki Declaration and the EEC guidelines for good clinical practice (1991) and was approved by the health authorities and the ethics committee systems in Sweden and Denmark.

\section{Results}

Nineteen patients completed the apomorphine test, 17 patients completed the dose finding and cross over phases, 16 patients completed week 2 of the maintenance phase, and 14 patients completed the whole study. Eight patients dropped out due to hypotension (three patients), unsatisfactory effect (two patients), exanthema, unclear off periods, and lack of motivation (one patient each).

All 17 patients who participated in the cross over phase completed the four days with apomorphine. In six out of 10 patients who started with placebo and three out of seven patients who received placebo after apomorphine, an obvious lack of drug effect during the placebo period made us shorten the placebo period to 24 to 72 hours for ethical reasons.

The maximal dose of apomorphine during the apomorphine test was on average 4.9 (range 1.6-6.4) mg. During the dose finding phase the maximal dose was on average 3.9 (1.0-8.0) $\mathrm{mg}$, whereas the optimal dose, according to the definition given, was on average $3.4(0.8-6 \cdot 0) \mathrm{mg}$, which remained unchanged during the cross over and maintenance phases.

During the cross over phase the dose of oral domperidone was $20 \mathrm{mg}$ three times daily, except for one patient whose dose was reduced to $20 \mathrm{mg}$ twice daily. A gradual withdrawal of domperidone was attempted during the maintenance phase, and five out of 14 patients were doing well without domperidone at the last study visit, whereas the remaining patients still needed $10-60 \mathrm{mg}$ per day, primarily to avoid nausea.

One pátient needed minor changes in levodopa dose during the cross over phase, and during the maintenance phase six patients needed minor changes in their levodopa or bromocriptine dose.

\section{EFFICACY}

\section{Dopaminergic response}

The dopaminergic response could be evaluated in 21 out of 22 patients who participated in the apomorphine test. One patient dropped out before any registration of dopaminergic response due to hypotension.

Twenty out of 21 patients fulfilled the criteria of satisfactory response in at least two out of four variables. One patient had a significant effect on one variable only $(100 \%$ reduction in tremor). As the patient had been treated with apomorphine for two years with a good response, the physician decided that she should continue in the study. 
Table 1 Mean (SD) daily duration of off periods (min/day) during the cross over phase

\begin{tabular}{lll}
\hline & $\begin{array}{l}\text { Staff } \\
(8 \text { h/day) }\end{array}$ & $\begin{array}{l}\text { Patients } \\
\text { (all wake time) }\end{array}$ \\
\hline Apomorphine & $120(91)$ & $303(151)$ \\
Placebo & $287(128)$ & $616(286)$ \\
Difference $(95 \% \mathrm{CI})$ & $-167(-231$ to -103$)$ & $-313(-469$ to -156$)$ \\
P value & $<0.0001$ & $<0.002$ \\
\hline
\end{tabular}

Table 2 Mean daily numbers of off periods during the cross over phase

\begin{tabular}{lll}
\hline & $\begin{array}{l}\text { Staff } \\
(8 \text { h/day) }\end{array}$ & $\begin{array}{l}\text { Patients } \\
\text { (all wake time) }\end{array}$ \\
\hline Apomorphine & $\begin{array}{l}2.61(0.6 \text { to } 11 \cdot 2) \\
\text { Placebo }\end{array}$ & $4 \cdot 70(1 \cdot 1$ to $20 \cdot 4)$ \\
Difference $(95 \% \mathrm{CI})$ & $34(0.4$ to $9 \cdot 4)$ & $4 \cdot 26(1 \cdot 1$ to $16 \cdot 1)$ \\
P value & $<0.02$ & $10(-11$ to 37$)$ \\
\hline
\end{tabular}

Values are geometric mean $(95 \% \mathrm{CI})$.

Table 3 Distribution of severity of off periods during the cross-over phase (total number of off periods (\% of total))

\begin{tabular}{llllll}
\hline & Mild & Moderate & Severe & Immobile & Total \\
\hline Apomorphine & $68(33)$ & $91(45)$ & $40(20)$ & $4(2)$ & $203(100)$ \\
Placebo & $13(12)$ & $49(46)$ & $39(36)$ & $6(6)$ & $107(100)$ \\
\hline
\end{tabular}

Values are total number of off periods (\%)

$P<0.00001$.

Table 4 Off periods registered by staff eight hours per day

\begin{tabular}{|c|c|c|c|c|c|}
\hline \multirow[b]{2}{*}{ Study phase } & \multicolumn{2}{|c|}{ No/day } & \multicolumn{2}{|c|}{$\begin{array}{l}\text { Severity } \\
\text { (scale 0-4) }\end{array}$} & \multirow{2}{*}{$\begin{array}{l}\text { Total duration } \\
\text { (min/day) } \\
\text { Mean (range) }\end{array}$} \\
\hline & No & Mean (range) & & Mean (range) & \\
\hline Screening & 19 & $2 \cdot 1(0 \cdot 0-4 \cdot 0)$ & 18 & $2 \cdot 2(1-4)$ & $206(10-510)$ \\
\hline Cross over 1 apomorphine & 7 & $3 \cdot 1(0 \cdot 8-5 \cdot 0)$ & 7 & $1.9(1-4)$ & $113(30-173)$ \\
\hline Cross over 2 placebo & 7 & $2 \cdot 0(0 \cdot 2-3 \cdot 0)$ & 7 & $2 \cdot 3(1-4)$ & $203(30-333)$ \\
\hline Cross over 1 placebo & 10 & $2 \cdot 7(0 \cdot 8-5 \cdot 7)$ & 10 & $2 \cdot 4(1-4)$ & $346(128-480)$ \\
\hline Cross over 2 apomorphine & 10 & $3 \cdot 1(0 \cdot 5-5 \cdot 0)$ & 10 & $1 \cdot 9(1-4)$ & $126(19-416)$ \\
\hline Maintenance week 8 & 14 & $2 \cdot 9(0 \cdot 0-5 \cdot 0)$ & 13 & $1 \cdot 8(1-3)$ & $99(25-310)$ \\
\hline
\end{tabular}

Population average and range of mean daily number and duration of off periods. Population average and range of severity of the off periods. Screening and cross over phases and end of the maintenance phase. All participating patients are included in the number of off period data, whereas only patients who experienced off periods are included in the severity and duration data. Cross over 1 and $2=$ first or second period in cross over phase.

Table 5 Off periods registered by patients in diaries (all time awake)

\begin{tabular}{lrll}
\hline & No & Number of off periods/day & Total duration (min/day) \\
\hline Screening phase & 18 & $4 \cdot 4(1 \cdot 7-7 \cdot 7)$ & $444(40-810)$ \\
Cross over 1 apomorphine & 6 & $5 \cdot 7(1 \cdot 0-9 \cdot 8)$ & $336(128-581)$ \\
Cross over 2 placebo & 6 & $5 \cdot 5(0 \cdot 8-13 \cdot 5)$ & $509(165-1188)$ \\
Cross over 1 placebo & 10 & $4 \cdot 7(2 \cdot 2-8 \cdot 0)$ & $681(315-1005)$ \\
Cross over 2 apomorphine & 10 & $5 \cdot 5(1 \cdot 0-9 \cdot 8)$ & $284(60-608)$ \\
Maintenance week 8 & 14 & $5 \cdot 8(1 \cdot 0-12 \cdot 7)$ & $253(30-485)$ \\
\hline
\end{tabular}

Population average and range of mean daily number and duration of off periods. Screening and cross over phases and end of the maintenance phase. Cross over 1 and $2=$ first or second period in cross over phase.

Table 6 Unified Parkinson's disease rating scale

\begin{tabular}{lcccc}
\hline Parts & Item No & $\begin{array}{l}\text { Screening } \\
(n=19)\end{array}$ & $\begin{array}{l}\text { Maintenance week } 4 \\
(n=14)\end{array}$ & $\begin{array}{l}\text { Maintenance week } 8 \\
(n=14)\end{array}$ \\
\hline I & $1-4$ & $1 \cdot 2(0 \cdot 0-3 \cdot 0)$ & $0 \cdot 7(0 \cdot 0-2 \cdot 0)$ & $0 \cdot 8(0 \cdot 0-3 \cdot 0)$ \\
II (off) & $5-17$ & $18 \cdot 3(7 \cdot 0-27 \cdot 0)$ & $15 \cdot 1(5 \cdot 0-24 \cdot 0)$ & $13 \cdot 2(5 \cdot 0-22 \cdot 0)$ \\
III (on) & $18-31$ & $9 \cdot 8(1 \cdot 5-22 \cdot 2)$ & $6 \cdot 9(0 \cdot 5-14 \cdot 4)$ & $6 \cdot 7(1 \cdot 0-14 \cdot 4)$ \\
IV & $32-42$ & $9 \cdot 5(5 \cdot 0-14 \cdot 0)$ & $7 \cdot 9(4 \cdot 0-13 \cdot 0)$ & $7 \cdot 7(3 \cdot 0-11 \cdot 0)$ \\
\hline
\end{tabular}

Values are mean score (range)

Part I = mentation, behaviour, and mood; part II = activities of daily living (during off periods); Part I = mentation, behaviour, and mood; part II = activities of daily living (during off periods);
part III = motor examination (examined in on period); part IV = complications of treatment.

\section{Effect on off periods}

Apomorphine caused a highly significant reduction $(58 \%)$ in the mean daily duration of off periods, as assessed by the staff, when apomorphine was compared with placebo. Similarly, apomorphine caused a reduction of $51 \%$ in the mean daily duration of off periods, as assessed by the patients (table 1 ).

The mean daily numbers of off periods, as assessed by the staff, showed a significant increase of $34 \%$ during apomorphine treatment, whereas there was no significant change according to the patients' assessments (table 2).

Table 3 shows the distribution of severity of the off periods, which was assessed by the staff. The Mantel-Haenszel analysis showed a highly significant treatment effect in favour of apomorphine on the severity of off periods.

Tables 4 and 5 show the population average and range of the mean daily number of off periods (for all participating patients) and their severity and mean daily duration (for those who had off periods) registered by the staff and by the patients. Compared with the screening phase, the off variables for the maintenance phase showed changes in the same direction as they did with apomorphine $v$ placebo during the cross over phase.

Clinical global impressions

In 12 of 14 patients who completed the maintenance phase much or very much improvement was reported at the last visit; two patients reported only minimal improvement. No patients were reported to have a worsening of their condition during the maintenance phase.

Effect on idiopathic Parkinson's disease symptoms Parts I, II, and IV of the UPDRS showed only minimal changes in score (table 6). In part III (motor examination during an on period) there seemed to be a slight reduction in total score (table 6), but for the primary parkinsonian symptoms (tremor, rigidity, and bradykinesia) only a slight reduction in bradykinesia score was seen (mean 4.9 (range $1.0-13.0$ ) during the screening phase $v 3 \cdot 5(0.5-7 \cdot 0)$ at week 4 of the maintenance period and $3 \cdot 3$ $(0 \cdot 0-7 \cdot 0)$ at week 8$)$.

\section{SAFETY}

There was a $67 \%(P<0.02)$ increase in the mean (SD) daily duration of involuntary movements with apomorphine (164 (132) $\mathrm{min} /$ day), compared with placebo (98 (102) $\mathrm{min} /$ day). The mean daily numbers of periods of involuntary movements (geometric mean values) were 2.19 with apomorphine and 1.62 with placebo, corresponding to an increase with apomorphine of $35 \%(P<0.05)$. No significant effect on the severity of the involuntary movements was seen.

Apart from involuntary movements, the most frequent adverse event was nausea with or without vomiting, which occurred in 16 out of 22 patients.

Among the 16 patients who participated in the eight week maintenance phase, 10 patients 

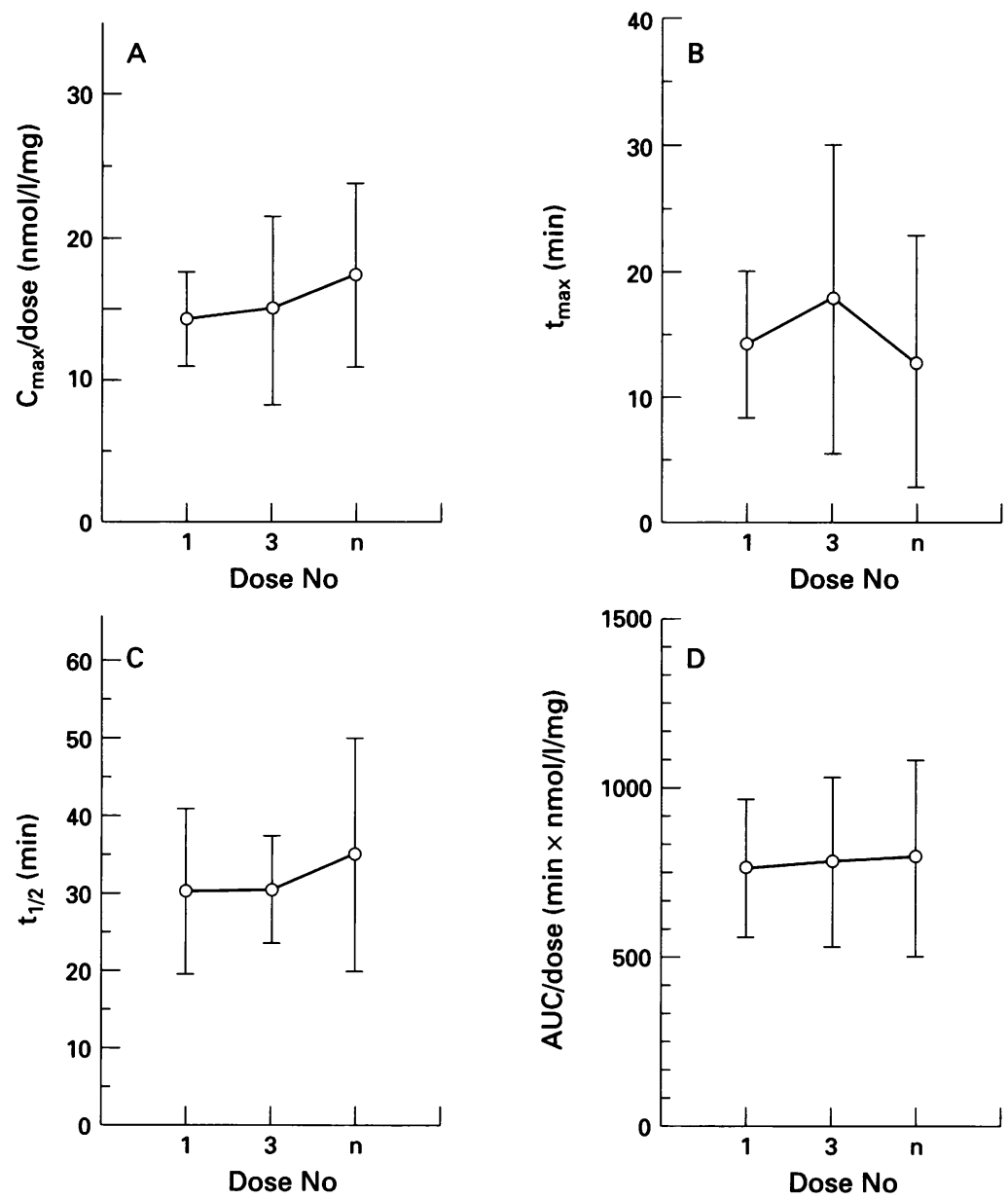

Mean values with $S D$ of $C_{\max } /$ dose $(A), t_{\max }(B), t_{1 / 2}(C)$, and $A U C /$ dose (D) after the first and the third dose of apomorphine in the dose finding phase and after one dose in the maintenance phase $(n=12,13)$.

experienced mild (five patients) or moderate (five patients) local irritation at the injection sites. Both haematomas and subcutaneous nodules were seen. Most patients, however, did not find the injections painful. No eosinophilia (as an indicator for local irritation) was seen.

When compared with pretreatment values substantial changes in systolic $(\geqslant \pm 30 \mathrm{~mm}$ $\mathrm{Hg})$ and diastolic $(\geqslant \pm 15 \mathrm{~mm} \mathrm{Hg})$ blood pressure and in heart rate ( $\geqslant \pm 15$ beats $/ \mathrm{min}$ ) were reported in a few patients only. Increases as well as decreases were seen. Substantial changes in blood pressure when rising from a supine to a standing position were also seen in a few patients only, and both increases and decreases were noted. In two of the three patients who dropped out because of unacceptable symptoms of hypotension, blood pressure and heart rate were not measured at the scheduled time because the staff were occupied in relieving the clinical symptoms. In the third patient the supine blood pressure was reduced from $125 / 80 \mathrm{~mm} \mathrm{Hg}$ before apomorphine injection to $110 / 70 \mathrm{~mm} \mathrm{Hg}$ after injection, and the standing blood pressure was reduced from $110 / 85$ to $90 / 65$, resulting in postural dizziness.

Other adverse events reported in more than one patient included dyskinesia and chorea, sweating and warmth, dizziness, headache, drowsiness, yawning, and rhinitis. The symp- toms were mild or moderate, except for a few cases of dizziness, which were characterised as severe.

Some values for haematology, biochemistry, and urinalysis were unsystematically out of the normal range. None of these changes were clinically relevant. No electrocardiographic changes were seen.

\section{SUITABILITY OF THE PEN}

According to the questionnaire 11 of 14 patients found their feeling of freedom increased after they had started apomorphine injections.

After eight weeks' use 13 of 14 patients were able to inject themselves and 11 of 13 patients found it very easy, easy, or rather easy to handle the pen. Most of the patients (11 of 14) were not afraid of performing the injections and only one patient found the injections painful.

\section{PHARMACOKINETICS}

Sixteen patients participated in the pharmacokinetic evaluation. For these patients values of $\mathrm{C}_{\max } /$ dose ranged from 7 to $32 \mathrm{nmol} / \mathrm{l} / \mathrm{mg}$ with values of $t_{\max }$ ranging from five to 45 minutes. Values of the apparent elimination half life $\left(t_{1 / 2}\right)$ ranged from 14.6 to 68.4 minutes, and values of the dose normalised AUC (AUC/dose) ranged from 401 to $1407 \mathrm{~min}$ $\times \mathrm{nmol} / \mathrm{l} / \mathrm{mg}$. In a few cases pharmacokinetic variables could not be calculated at all three occasions and, to avoid any bias, data from these patients were omitted from calculation of the mean values. As shown in the figure these values were fairly constant at the three occasions of blood sampling. This impression was confirmed by the statistical analysis (repeated measures ANOVA), which did not show any significant changes.

\section{Discussion}

Apomorphine in this study proved to have a definite effect on off phenomena in idiopathic Parkinson's disease, reducing both severity and duration of the off periods. Our patients had classic parkinsonian symptoms (tremor, rigidity, and bradykinesia) as well as other kinds of off phenomena (dysphoria and painful dystonia), and these were equally successfully treated with apomorphine. The $58 \%$ reduction in mean daily duration of off periods (staff evaluation) is in accordance with previous results. ${ }^{92425}$ We think that the treatment effect on this variable was of major importance for the patients' increased feeling of freedom. The percentage reduction in daily off time according to the patients' diaries was slightly lower than that assessed by the staff. This may be due to subjective "off" symptoms, which occurred before apomorphine was given and which could not be evaluated by the staff. The finding that the mean daily duration of off periods after eight weeks of maintenance treatment was profoundly reduced compared with the findings during the screening phase suggests a good effect of apomorphine, also in long term treatment. 
The finding that the daily number of off periods increased during apomorphine treatment can be explained by the fact that the treatment effect was of short duration $(0.5-$ 2.5 hours), so that intermittent treatment with apomorphine may have caused a "fragmentation" of otherwise longer off periods.

The fact that most patients who completed the maintenance phase reported much or very much improvement, whereas their off phenomena had not been entirely cured, may reflect a positive impact on the patient's total situation by even a minor reduction in severely disabling off periods.

Although not statistically analysed, the effect of apomorphine on the variables of UPDRS seemed to be modest. This is probably because apomorphine causes quantitative changes in off phenomena, but does not change the quality of the symptoms to any large extent, as evaluated by UPDRS.

In the apomorphine test, placebo caused a positive response on one or more variables in several patients. When comparing the number and severity of off periods, however, during the cross over phase with the data from the screening phase there was no placebo response (tables 4 and 5), probably because the treatment was no longer entirely new to the patients.

Because dose titration until an optimal effect or occurrence of side effects was encouraged, the maximal doses given in the dose finding period were slightly higher than the optimal doses. The mean optimal dose of $3.4 \mathrm{mg}$ is higher than that found by Frankel et al $(2 \cdot 2 \mathrm{mg}) .^{9}$

The pharmacokinetic evaluation comprised two doses in the dose finding phase and one dose in the maintenance phase. This design was used to analyse for dose linearity of concentrations and for altered pharmacokinetics with time in a multiple dose regimen. The dose normalised values of $C_{\max }$ and $A U C$ as well as $t_{\max }$ and $t_{1 / 2}$ did not change significantly at the three occasions. Thus there was no evidence of deviation from dose linearity or for altered pharmacokinetics. In a pharmacokinetic study of apomorphine in patients with idiopathic Parkinson's disease, Gancher et al found lower values of $t_{\max }$ (mean $9.2 \mathrm{~min}$ ) and higher values of $\mathrm{C}_{\max }$ /dose (mean 31.5 $\mathrm{nmol} / \mathrm{l} / \mathrm{mg}$ ) than those of the present study. ${ }^{26}$ The reason for these differences is not clear, but one possible explanation is the use of different drug formulations influencing the rates of absorption. Gancher et $a^{26}$ used solutions of $1-2 \mathrm{mg} / \mathrm{ml}$ apomorphine in water whereas we used a preserved formulation containing $10 \mathrm{mg} / \mathrm{ml}$ apomorphine. Other variables estimated by Gancher et al ( $\mathrm{t}_{1 / 2}$, AUC) were in accordance with our results.

The more intensive stimulation of dopamine receptors after addition of apomorphine is probably the reason for the increase in the mean daily duration of involuntary movement periods. In the present study the doses of concomitant antiparkinsonian drugs were kept rather constant to obtain a reliable evaluation of apomorphine effects, but previ- ous authors have reported the successful reduction in levodopa doses when apomorphine was added. ${ }^{24}$ Whether the combination of levodopa and apomorphine may cause a reduction in the severity of adverse treatment effects remains controversial..$^{913}$

Apart from involuntary movements, nausea with or without vomiting was the most frequent adverse event and in several patients this necessitated continuous domperidone treatment. We think that the maintenance dose of domperidone should be kept at a minimum, considering that domperidone has an antidopaminergic effect, although this is mainly peripheral. On the other hand, the three cases of orthostatic hypotension occurring early after initiation of apomorphine treatment might have been prevented, had the initial domperidone treatment been of longer duration.

The subcutaneous treatment with apomorphine caused development of nodules in most patients. In none of the cases did the nodules cause major problems, but injection into affected skin areas should probably be avoided, as absorption may be unpredictable.

In the present study there were no clear differences in demographic data, on the basis of which we are able to propose criteria for the selection of patients likely to benefit from apomorphine. Neither did we see any factors that were obviously predictive for the occurrence of hypotension, the side effect that most often led to the withdrawal of apomorphine. Patients with hypotension as a symptom of their idiopathic Parkinson's disease were not included in this study, but it is likely that such patients are more susceptible to the hypotensive effect of apomorphine. The initial apomorphine test was of some help in predicting possible side effects, as two of the three patients who experienced significant hypotension did so during the test. The apomorphine test, as performed in this study, did not provide any crucial information on the long term therapeutic effect of apomorphine, as all patients showed a positive response to the test, whereas two patients left the study later on due to an unsatisfactory effect. This can partly be explained by an initial placebo effect, as discussed earlier.

Several patients learned to handle the pen on their own, but it remains a problem that many patients who have severe idiopathic Parkinson's disease are not able to inject themselves during off periods and therefore remain dependent on others. As an alternative to subcutaneous injections, the continuous or intermittent subcutaneous infusion of apomorphine by means of a portable pump has been investigated in several studies..$^{6-9}$ A good clinical effect is often obtained, but the almost invariable formation of troublesome subcutaneous nodules is a disadvantage. Intranasal administration causes local irritation to the mucosa, ${ }^{2728}$ and with sublingual ${ }^{29}{ }^{30}$ and rec$\mathrm{tal}^{31}$ administration the absorption rate in many patients is too slow. The development of new methods of administration is therefore still needed. 
More than $50 \%$ of our patients, however, all belonging to a difficult to treat population, completed the study and experienced benefit from the treatment, and we conclude that subcutaneous injections of apomorphine by means of a pen are valuable in advanced Parkinson's disease.

This study was performed with considerable practical help from Ms T Vejlgaard, Ms A Gerding, Ms C Jönsson, Ms M Højberg, and Ms P Rasmussen. We also thank Ms M Hansen who performed the assay of plasma for apomorphine, and $\mathrm{Mr} \mathrm{D}$ Edwards, Novo Nordisk A/S, and Mr J Willumsen, who provided great help in the statistical evaluation of the results.

1 Schwab RS, Amador LV, Lettvin JY. Apomorphine in Parkinson's disease. Transactions of the American Neurological Association 1951;76:251-3.

2 Braham I, Sarova-Pinhas I, Goldhammer Y. Apomorphine in parkinsonian tremor. BMF 1970;3:768.

3 Castaigne P, Laplane D, Dordain G. Clinical experimentation with apomorphine in Parkinson's disease. Res tation with apomorphine in Parkinson's dis

4 Cotzias GC, Papavasiliou PS, Tolosa E, Mendez JS, BellMidura M. Treatment of Parkinson's disease with apomorphines. N Engl F Med 1976;294:567-72.

5 Yahr MD, Clough GC, Bergmann KJ. Cholinergic and dopaminergic mechanisms in Parkinson's disease after longterm levodopa administration. Lancet 1982;ii: 709-10.

6 Stibe $\mathrm{CMH}$, Kempster PA, Lees AJ, Stern GM. Subcutaneous apomorphine in parkinsonian on-off oscillations. Lancet 1988;iL403-6.

7 Lees AJ, Stibe CM, Kempster PA, Stern GM. Long-term use of continuous or intermittent subcutaneous adminisuse of continuous or intermittent subcutaneous adminisinduced motor oscillations [abstract]. Neurology 1989; 39(suppl 1):365.

8 Poewe W, Kleedorfer B, Gerstenbrand F, Oertel WH. Die Behandlung von Parkinson Patienten mit L-Dopawirkungsfluktuation mittels subkutanen Apomorphingaben. Akta Neurologica 1989;16:73-7.

9 Frankel JP, Lees AJ, Kempster PA, Stern GM Subcutaneous apomorphine in the treatment of Parkinson's disease. $\mathcal{F}$ Neurol Neurosurg Psychiatry 1990 53:96-101

10 Ernst AM. Relation between the action of dopamine and apomorphine and their $o$-methylated derivatives upon the CNS. Psychopharmacologia 1965;7:391-9.

11 Gancher ST, Woodward WR, Gliessman P, Boucher B, Nutt JG. The short-duration response to apomorphine: implications for the mechanism of dopaminergic effects in parkinsonism. Ann Neurol 1990;27:660-5.
12 Cotzias GC, Papavasiliou PS, Fehling C, Kaufmann B, Mena I. Similarities between neurologic effects of Ldopa and of apomorphine. N Engl F Med 1970;282:31-3.

13 Düby SE, Cotzias GC, Papavasiliou PS, Lawrence WH. Injected apomorphine and orally administered levodopa in parkinsonism. Arch Neurol 1972;27:474-80.

14 Frattola L, Albizzati MG, Bassi S, Ferrarese C, Trabucchi M. "On-off" phenomena, dyskinesias and dystonias: comparison of lisuride versus apomorphine acute treatment. Acta Neurol Scand 1982;66:227-36.

15 Hardie RJ, Lees AJ, Stern GM. On-off fluctuations in Parkinson's disease. A clinical and neuropharmacologiParkinson's disease. A clinical and
cal study. Brain 1984;107:487-506.

16 Barker R, Duncan J, Lees AJ. Subcutaneous apomorphine as a diagnostic test for dopaminergic responsiveness in parkinsonian syndrom

17 Oertel WH, Gasser T, Ippisch R, Trenkwalder C, Poewe $W$. Apomorphine test for dopaminergic responsiveness. Lancet 1989;i:1263.

18 Hughes AJ, Lees AJ, Stern GM. Apomorphine test to predict dopaminergic responsiveness in parkinsonian syndromes. Lancet 1990;336:32-4.

19 Langston JW, Widner H, Goetz CG, et al. Core assessment program for intracerebral transplantations (CAPIT). Mov Disord 1992;7:2-13.

20 Anonymous. Clinical global impressions (item 2). Psychopharmacology 1985;21:839-43.

21 Lang AE. Clinical rating scales and videotype analysis. In: Koller WC, Paulson G, eds. Therapy of Parkinson's disease. New York: Marcel Dekker, 1989, appendix Iisease. 16 . 23 .

22 Heinzel G, Woloszczak R, Thomann P. TopFit 2.0. Pharmacokinetic and pharmacodynamic data analysis for the PC. Stuttgart: Gustav Fischer 1993.

23 Mantel N. Chi ${ }^{2}$-tests with one degree of freedom: extensions of the Mantel-Haenszel procedure. Fournal of the American Statistical Association 1963;58:690-700.

24 Pollak P, Champay AS, Hommel M, Perret JE, Benabid AL. Subcutaneous apomorphine in Parkinson's disease. f Neurol Neurosurg Psychiatry 1989;52:544.

25 Hughes AJ, Bishop S, Kleedorfer B, et al. Subcutaneous apomorphine in Parkinson's disease: response to chronic administration for up to five years. Mov Disord 1993; 8:165-70.

26 Gancher ST, Woodward WR, Boucher B, Nutt JG. Peripheral pharmacokinetics of apomorphine in humans. Peripheral pharmacokinetics of apomorphine in humans.

27 Kapoor R, Turjanski N, Frankel J, Kleedorfer B, Lees A, Stern G. Intranasal apomorphine: a new treatment in Parkinson's disease. F Neurol Neurosurg Psychiatry 1990; 53:1015.

28 Kleedorfer B, Turjanski J, Ryan R, Lees AJ, Milroy C, Stern GM. Intranasal apomorphine in Parkinson's disease. Neurology 1991;41:761-2.

29 Durif F, Deffond D, Tournilhac M. Efficacy of sublingual apomorphine in Parkinson's disease. 7 Neurol Neurosurg Psychiatry 1990;53:1105.

30 Gancher ST, Nutt JG, Woodward WR. Absorption of apomorphine by various routes in parkinsonism. Mov Disord 1991;6:212-6.

31 Hughes AJ, Bishop S, Lees AJ, Stern GM, Webster R, Bovingdon M. Rectal apomorphine in Parkinson's disease. Lancet 1991;337:118. 